\title{
A New Approach to Evaluation of the Atmospheric Effects on Upwelling Radiance from the Ocean
}

\author{
by \\ Tsutomu Takashima \\ Meteorological Research Institute, Tsukuba, Japan
}

(Received Feb. 24, 1983; Revised April 8, 1983)

\begin{abstract}
The reflection matrix of radiation just above the ocean surface is derived in a form suitable for the use of adding method. The air-water interface is separated by a rufled surface, whose angular dependent reflection and transmission properties are calculated based on a Gaussian distribution of wave slopes (Cox and Munk, 1956). At present, the ocean is assumed to be vertically inhomogeneous, and its bottom to absorb all incident radiation. Polarization is included in the derivation of the equation. The reflection matrix of radiation thus derived enables us the computations of space radiance at the top of the atmosphere. The tiresome computation due to the polarity effect of radiation is overcome by the present method. Finally a sample computation is carried out in a scalar form.
\end{abstract}

\section{Introduction}

It is evident that remote sensing techniques from the Earth satellites have certain advantages since they make possible frequent observations in the area concerned and a wide coverage of the earch. Hence these techniques are being used operationally as a tool for determining sea surface temperature and cloud distribution. More recently, the increased demand for such hydrological information as the aerial coverage of ice and snow as well as the chlorophyll distribution has resulted in the use of remote sensing from the Earth satellites carrying high-resolution radiometers such as MSS of Landsat, CZCS of Nimbus and AVHRR of NOAA satellites. However, there are frequent ambiguities in the data obtained by these methods even after enhancement techniques are adopted in order to improve the data. This has resulted in a trend to use a combination of infrared and visible data in order to get more independent information than can be deduced from data taken in one single channel. This trend increases with higher accuracy requirement in the analyses. Hence in the visible region of the spectrum, a more accurate atmosphere-oceanic model is required to compare satellite borne data with theoretical computations.

Raschke (1972) has considered the effect of the ocean wave on radiation in an atmosphere-ocean system by an iterative method. Plass et al. (1976) computed the radiance distribution over a ruffled sea by the Monte Carlo method. Tanaka and Nakajima (1977) examined the effects of the index of refraction of hydrosols and their concentration on the radiation field of the atmosphere-ocean system by the matrix method, which assumed the ocean surface to be smooth. Ueno (1981) obtained the effective surface albedo inversely from space measurements by making use of the invariant imbedding method, which assumed the ocean surface to be a perfect specular reflector.

In this paper, a method of computing the atmospheric effect on the upwelling radiation 
from the ocean is derived in a form suitable for the use of the adding method. The effect of the ocean wave on the upwelling radiation is also taken into account. Polarization is considered in the derivation of equations. This method has a certain advantage in that we can thus avoid the tiresome treatment of the polarity effect of radiation (Ueno, 1960) caused by the inhomogeneous atmosphere. Computations including the effect of polarization are under way.

\section{Derivation of equation}

Consider an atmosphere which is illuminated by the parallel radiation $\overline{\pi F}(1 \times 4$ matrix $)$ at the top of the atmosphere in the direction $\Omega_{0}\left(-\mu_{0}, \phi_{0}\right)$, where symbols $\mu_{0}$ and $\phi_{0}$ denote the direction cosine and the azimuth, respectively. In the present work, $\overline{\pi F}$ is put to be $[1 / 2,1 / 2,0,0]$ (Fig. 1). The atmosphere is assumed to be horizontally homogeneous and vertically inhomogeneous, and bounded by a homogeneous ocean surface. The surface is simulated by many facets whose slopes are distributed according to the isotropic Gaussian law with respect to surface wind. The refection matrix $\bar{S}_{w}^{e}$ due to the ocean is composed of a reflection phase matrix of the ocean surface $\bar{R}\left(n,+\Omega,-\Omega^{\prime}\right)$ where the incident downward radiation is reflected upwards directly by the ocean surface, and a phase matrix of reflection due to scatterings in the ocean $\bar{S}_{w}^{u}\left(\tau_{w},+\Omega,-\Omega^{\prime}\right)$, where the refracted radiation from the atmosphere into the ocean is

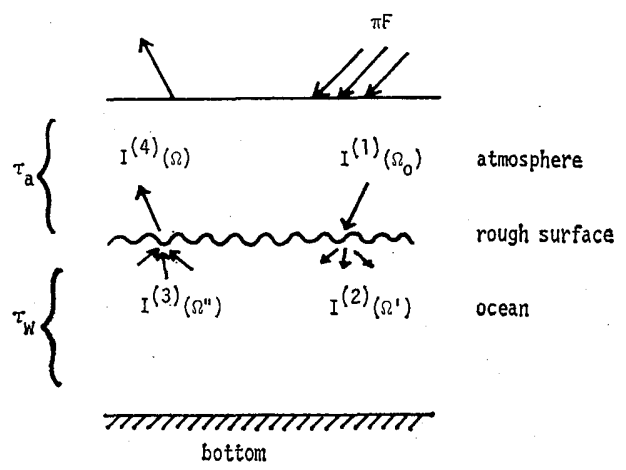

Fig. 1. Diagram showing radiative transfer in the atmosphere-ocean system. refiected difiusely by the water molecules and hydrosols in the ocean and then transmitted upwards to the atmosphere. Consequently $\bar{S}_{w}^{e}$ is expressed in the form:

$$
\begin{aligned}
& \bar{S}_{w}^{e}\left(\tau_{w},+\Omega,-\Omega^{\prime}\right) \\
& \quad=\bar{S}_{w}^{u}\left(\tau_{w},+\Omega,-\Omega^{\prime}\right)+\vec{R}\left(n,+\Omega,-\Omega^{\prime}\right)
\end{aligned}
$$

where symbols $\tau_{w}, n,+\Omega$ and $-\Omega^{\prime}$ denote the optical thickness of the ocean, refractive index of the ocean water at a given wavelength, solid angles of upwelling direction and downward direction, respectively.

If the sea surface were absolutely calm, a single image of the sun could be seen reflected on a specular surface. In this case the reflection matrix of a specular surface could be expressed by the following diagonal matrix $\bar{R}_{s p}\left(n, \chi_{t}, \chi_{i}\right)$ in Chandrasekhar's representation of Stokes vector:

$$
\bar{R}_{s p}=\left|\begin{array}{llll}
r_{\| 1}^{9} & & \\
& r_{\perp}^{2} & & \\
& & -r_{11} r_{\perp} & \\
& & & -r_{\| 1} r_{\perp}
\end{array}\right|
$$

where elements $r_{11}$ and $r_{\perp}$ are given by

$$
\begin{aligned}
& r_{11}=-\frac{n \cos \left(\chi_{i}\right)-\cos \left(\chi_{t}\right)}{n \cos \left(\chi_{i}\right)+\cos \left(\chi_{t}\right)} \\
& r_{\perp}=\frac{\cos \left(\chi_{i}\right)-n \cos \left(\chi_{t}\right)}{\cos \left(\chi_{i}\right)+n \cos \left(\chi_{t}\right)}
\end{aligned}
$$

where the ratio of the refractive index of the ocean $n_{2}$ to that of the atmosphere $n_{1}$ is expressed by $n\left(\equiv n_{2} / n_{1}\right) . \quad \chi_{t}$ and $\chi_{i}$ stand for the incident angle normal to the surface and that of the transmitted radiation, respectively. Similarly the transmission matrix of a specular surface is given by the following diagonal matrix :

$$
\bar{T}_{s,}=|n| \frac{\cos \left(\chi_{t}\right)}{\cos \left(\chi_{i}\right)}\left|\begin{array}{llll}
t_{11}^{2} & & & \\
& t_{\perp}^{2} & & \\
& & -t_{11} t_{\perp} & \\
& & & -t_{11} t_{\perp}
\end{array}\right|
$$

where elements $t_{11}$ and $t_{\perp}$ denote

$$
\begin{aligned}
& t_{11}=\frac{2 \cos \left(\chi_{i}\right)}{n \cos \left(\chi_{i}\right)+\cos \left(\chi_{t}\right)} \\
& t_{\perp}=\frac{2 \cos \left(\chi_{i}\right)}{\cos \left(\chi_{i}\right)+n \cos \left(\chi_{t}\right)}
\end{aligned}
$$


It should be noted that reflectivity $\rho$ and transmissivity $t$ can be related to

$$
\rho+t=1
$$

in agreement with the law of conservation of energy. Where $\rho$ and $t$ are expressed by

$$
\begin{aligned}
& \rho=1 / 2\left(\left|r_{11}\right|^{2}+\left|r_{\perp}\right|^{2}\right) \\
& t=1 / 2|n| \frac{\cos \left(\chi_{t}\right)}{\cos \left(\chi_{i}\right)}\left(\left|t_{11}\right|^{2}+\left|t_{\perp}\right|^{2}\right)
\end{aligned}
$$

Cox and Munk (1955) simulated the ocean surface numerically by many facets, of which the slope components are distributed according to the Gaussian law with respect to surface wind. The distribution is isotropic in the case of distribution independent of wind direction, but anisotropic in the case of distribution depending upon wind direction. In this model surface, parameters $\chi_{i}$ and $\chi_{t}$ are defined by the angles from normal direction to the orientation of facets. According to Snell's law of refraction, these are related to

$$
\sin \left(\chi_{i}\right)=p \sin \left(\chi_{t}\right)
$$

where $p$ is a real part of refractive index $n$ $(=p-i q)$. Parameters $\chi_{i}$ and $\chi_{t}$ can be converted to those of the meridian coordinates, where zenith and azimuth are defined by a point on a smooth plane ocean surface, observer and incident solar direction. The geometry of the facet, showing the incident and reflection directions, is illustrated in Fig. 2, where symbols $\left(\theta^{\prime}, \phi^{\prime}\right),(\theta, \phi)$ and $\left(\theta_{0}, \phi_{0}\right)$ represent the directional parameters, zenith and azimuth, of incident, emergent directions, and direction normal to the facet, respectively; OA indicates

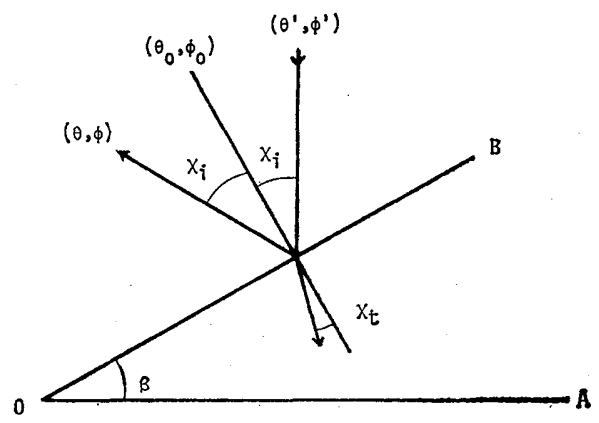

Fig. 2. Geometry of the facets. the averaged smooth plane ocean surface, and $\mathrm{OB}$ and $\beta$ the direction tangent to a facet and tilt, respectively.

First of all, in the case of the isotropic Gaussian distribution,

$$
P\left(z_{x}, z_{y}\right)=\left(\pi \sigma^{2}\right)^{-1} \exp \left[-\left(z_{x}^{2}+z_{y}^{2}\right) / \sigma^{2}\right]
$$

where $z_{x}$ and $z_{y}$ represent the slope components in the $X$-and $Y$-directions in the sun vertical and the plane perpendicular to it, respectively. Cox and Munk found from airplane photographs that the mean square slope, regardless of the direction, $\sigma^{2}=\left\langle z_{x}^{2}+z_{y}^{2}\right\rangle_{A V}$, increases with the "masthead" wind speed $w(\mathrm{~m} / \mathrm{sec})$ according to

$$
\sigma^{2}=0.003+0.00512 \times w \pm 0.004
$$

In the presence of a slick this value is reduced by a factor of two or three. The azimuth of ascent, $\alpha$, and the tilt, $\beta$, are related to the slope components $z_{x}$ and $z_{y}$ according to

$$
\begin{aligned}
& z_{x}=\sin \alpha \tan \beta \\
& z_{y}=\cos \alpha \tan \beta
\end{aligned}
$$

The slope components $z_{x}$ and $z_{y}$ can be converted to parameters regarding the incident and reflected directions with the aid of spherical trigonometry (Takashima and Takayama, 1981). Therefore the isotropic Gaussian distribution can be expressed in the form,

$$
P\left(\Omega,-\Omega^{\prime}\right)=\left(\pi \sigma^{2}\right)^{-1} \exp \left[(1-2 a) / \sigma^{2}\right]
$$

where parameter a is expressed by the zenith angles $\left(\theta, \theta^{\prime}\right)$ and the azimuths $\left(\phi, \phi^{\prime}\right)$ of the incident and emergent radiation, respectively in the form:

$$
\begin{aligned}
& a\left(\theta, \theta^{\prime}, \phi-\phi^{\prime}\right) \\
= & \frac{1+\cos \theta \cos \theta^{\prime}+\sin \theta \sin \theta^{\prime} \cos \left(\phi-\phi^{\prime}\right)}{\left(\cos \theta+\cos \theta^{\prime}\right)^{2}}
\end{aligned}
$$

and

$$
\cos \chi_{i} \sec \beta=a\left(\cos \theta^{\prime}+\cos \theta\right)
$$

The slope parameters $\delta z_{x} \delta z_{y}$ can also be converted to the emergent solid angle $d \Omega$ according to

$$
\delta z_{x} \delta z_{y}=a /\left(\cos \theta^{\prime}+\cos \theta\right) d \Omega
$$

where $a>0$ at $0<\theta ; \theta^{\prime}<\pi / 2$. 
Let us derive the reflection matrix of the ocean in a form suitable for the adding method. When the incident radiation upon the ocean surface is defined by $\bar{I}^{(1)}\left(-\Omega_{0}\right)$, where the direction $\Omega_{0}$ may be different from that of the sun, the upwelling radiation just above the ocean surface $\bar{I}^{(4)}(+\Omega)$ can be expressed by the reflection matrix of the ocean as follows:

$$
\begin{aligned}
& \bar{I}^{(4)}(+\Omega) \\
= & (1 / 4 \pi \mu) \bar{S}_{w}^{e}\left(\tau_{w},+\Omega,-\Omega_{0}\right) \bar{I}^{(1)}\left(-\Omega_{0}\right)
\end{aligned}
$$

It should be noted that $\bar{I}^{(4)}(+\Omega)$ is different from the radiation observed just above the ocean surface in the atmosphere-ocean system. The radiation observed just above the ocean surface should be taken into account in discussing the interaction of radiation in the atmosphere-ocean and ocean surface. Substitution of eq. (1) into eq. (20) yields

$$
\begin{aligned}
& \bar{I}^{(4)}(+\Omega) \\
= & (1 / 4 \pi \mu) \bar{S}_{w}^{u}\left(\tau_{w},+\Omega,-\Omega_{0}\right) \bar{I}^{(1)}\left(-\Omega_{0}\right) \\
& +(1 / 4 \pi \mu) \bar{R}\left(n,+\Omega,-\Omega_{0}\right) \bar{I}^{(1)}\left(-\Omega_{0}\right)
\end{aligned}
$$

The first term on the righthand side of eq. (21) is the radiation reflected diffusely in the ocean. This term is additive to the radiation reflected directly by the ocean surface. Thus, upon computing the upwelling radiation from the top of the atmosphere by taking into account the polarization effect, we can avoid the tiresome treatment of the polarity effect caused by the vertically inhomogeneous and horizontally homogeneous atmosphere (Takashima, 1973, 1975).

Similarly, when the transmitted radiation just beneath the ocean surface is defined by $\bar{I}^{(2)}\left(-\Omega^{\prime}\right)$, the upwelling radiation just beneath the ocean surface $I^{(3)}\left(+\Omega^{\prime \prime}\right)$ can be expressed by the resection matrix of the ocean as follows :

$$
\begin{aligned}
& \bar{I}^{(3)}\left(+\Omega^{\prime \prime}\right) \\
= & \left(1 / 4 \pi \mu^{\prime \prime}\right) \bar{S}_{w}\left(\tau_{w},+\Omega^{\prime \prime},-\Omega^{\prime}\right) \bar{I}^{(2)}\left(-\Omega^{\prime}\right)
\end{aligned}
$$

where the reflection matrix of radiation $\bar{S}_{w}$ is derived by taking into account the scatterings of water molecules and hydrosols independently of the atmosphere-ocean system. It should be noted that the matrix $\bar{S}_{w}^{u}$ is different from that of $\bar{S}_{w}$, since the radiation from the ocean is refracted by the ocean surface characteristics when the radiation is transmitted upwards from the ocean.

Let us consider the relation between matrices $\bar{I}^{(1)}$ and $\bar{I}^{(2)}$, and between matrices $\bar{I}^{(4)}$ and $\bar{I}^{(3)}$, respectively, by taking into account the ocean surface characteristics. As for the orientation of a facet, the projected area normal to the incoming rays $d S$ just above the ocean surface is expressed by

$$
d S=\cos \left(\chi_{i}\right) \sec (\beta) P\left(z_{x}, z_{y}\right) \delta z_{x} \delta z_{y}
$$

where the area projected to the plane parallel to the horizontal smooth ocean surface is put to be unity. With the aid of eqs. (16), (18) and (19), eq. (23) can be written as

$$
d S=\left(a^{2} / \pi \sigma^{2}\right) \exp \left[(1-2 a) / \sigma^{2}\right] d \Omega
$$

The incident radiation on the facet is, therefore,

$$
\left(a^{2} / \pi \sigma^{2}\right) \exp \left[(1-2 a) / \sigma^{2}\right] d \Omega \bar{I}^{(1)}\left(-\Omega_{0}\right)
$$

The refracted radiation by the slope within the limits $z_{x} \pm 1 / 2 \delta z_{x}, z_{y} \pm \delta z_{y}$, to the direction $\chi_{t}$ is

$$
\begin{aligned}
\left(a^{2} / \pi \sigma^{2}\right) \exp [(1 & \left.-2 a) / \sigma^{2}\right] d \Omega \\
& \times \bar{T}_{s p}\left(\chi_{t}, \chi_{i}\right) \bar{I}^{(1)}\left(-\Omega_{0}\right)
\end{aligned}
$$

which can be written as

$$
\begin{array}{r}
\bar{I}^{(2)}\left(\chi_{t}, \chi_{i}\right)=\left(a^{2} / \pi \sigma^{2}\right) \exp \left[(1-2 a) / \sigma^{2}\right] \\
\times \bar{T}_{s p}\left(\chi_{t}, \chi_{i}\right) \bar{I}^{(1)}\left(-\Omega_{0}\right)
\end{array}
$$

or by introducing the refraction matrix of the ocean surface $\bar{R}_{T}\left(-\Omega^{\prime},-\Omega_{0}\right)$ as

$$
\begin{aligned}
& \bar{R}_{T}\left(-\Omega^{\prime},-\Omega_{0}\right)=\left(4 a^{2} \mu^{\prime}\right) / \sigma^{2} \\
& \quad \times \exp \left[(1-2 a) / \sigma^{2}\right] \bar{T}_{s p}\left(-\Omega^{\prime},-\Omega_{0}\right)
\end{aligned}
$$

The matrix $\bar{I}^{(2)}$ is related to that of $\bar{I}^{(1)}$ as follows :

$$
\begin{aligned}
& \bar{I}^{(2)}\left(-\Omega^{\prime},-\Omega_{0}\right) \\
= & \left(1 / 4 \pi \mu^{\prime}\right) \bar{R}_{T}\left(-\Omega^{\prime},-\Omega_{0}\right) \bar{I}^{(1)}\left(-\Omega_{0}\right)
\end{aligned}
$$

For a reflected radiation by the water molecules and suspended particles, the upwelling radiation is expressed by the following hemispherical integration: 


$$
\begin{aligned}
& \bar{I}^{(3)}\left(+\Omega^{\prime \prime}\right) \\
= & \left(1 / 4 \pi \mu^{\prime \prime}\right) \int_{2 \pi} \bar{S}_{w}\left(\tau_{w},+\Omega^{\prime \prime},-\Omega^{\prime}\right) \bar{I}^{(2)}\left(-\Omega^{\prime}\right) d \Omega^{\prime} \\
\text { or } \quad & \mu^{\prime \prime} \bar{I}^{(3)}\left(+\Omega^{\prime \prime}\right) \\
= & \left\{\bar{S}_{w}\left(\tau_{w},+\Omega^{\prime \prime},-\Omega^{\prime}\right) \mu^{\prime} \bar{I}^{(2)}\left(-\Omega^{\prime}\right)\right\}
\end{aligned}
$$

where the hemispherical integration \{\} introduced by Sekera (1966) is given by

$$
\begin{aligned}
& \left\{\bar{A}\left(\Omega^{\prime}\right) \bar{B}\left(\Omega^{\prime}\right)\right\} \\
= & 1 / 4 \pi \int_{0}^{2 \pi} \int_{0}^{1} \bar{A}\left(\Omega^{\prime}\right) \bar{B}\left(\Omega^{\prime}\right) d \mu^{\prime} d \phi^{\prime} / \mu^{\prime}
\end{aligned}
$$

or eq. (31) can be simply written in the following form without any confusion,

$$
\mu \bar{I}^{(3)}=\bar{S}_{w} \mu^{\prime} \bar{I}^{(2)}
$$

Then the radiation $\mu \bar{I}^{(3)}$ in eq. (33) is partly reflected downwards by the atmosphere-ocean boundary and reflected again upwards by the suspended particles in the ocean. Eventually upward radiation $\bar{I}^{(3)}$ can be expressed by the following infinite series of hemispherical integrations :

$$
\begin{aligned}
\mu \bar{I}^{(3)}= & \bar{S}_{w} \mu^{\prime} \bar{I}^{(2)}+\bar{S}_{w} \bar{R} \bar{S}_{w} \mu^{\prime} \bar{I}^{(2)} \\
& +\bar{S}_{w} \bar{R} \bar{S}_{w} \bar{R} \bar{S}_{w} \mu^{\prime} \bar{I}^{(2)}+\cdots
\end{aligned}
$$

where $\bar{R}$ denotes the reflection matrix of radiation defined in eq. (21). The second term on the righthand side of eq. (34) corresponds to the radiation reflected diffusely downwards by the boundary and reflected again upwards by the suspended particles in the ocean. The third term corresponds to the radiation where these reflection processes are repeated over again.

The transmitted radiation from the ocean to the atmosphere $\bar{I}^{(4)}(+\Omega)$ is related to the upwelling radiation from the ocean $\bar{I}^{(3)}\left(+\Omega^{\prime \prime}\right)$ as follows:

$$
\begin{aligned}
& \bar{I}^{(4)}(+\Omega) \\
= & (1 / 4 \pi \mu) \int_{2 \pi} \bar{R}_{T}\left(+\Omega,+\Omega^{\prime \prime}\right) \bar{I}^{(3)}\left(+\Omega^{\prime \prime}\right) d \Omega^{\prime \prime}
\end{aligned}
$$

Therefore,

$$
\begin{aligned}
& \bar{I}^{(4)}(+\Omega) \\
= & (1 / 4 \pi \mu) \int_{2 \pi} \bar{R}_{T}\left(+\Omega,+\Omega^{\prime \prime}\right) d \Omega^{\prime \prime} \\
& \times\left(1 / 4 \pi \mu^{\prime \prime}\right) \int_{2 \pi} \bar{S}_{w}\left(\tau_{w},+\Omega^{\prime \prime},-\Omega^{\prime}\right) \\
& \times\left(1 / 4 \pi \mu^{\prime}\right) \bar{R}_{T}\left(-\Omega^{\prime}, \Omega_{0}\right) d \Omega^{\prime} \bar{I}^{(1)}\left(-\Omega_{0}\right)+\cdots
\end{aligned}
$$

or

$$
\begin{aligned}
& \bar{S}_{w}^{u}\left(\tau_{w},+\Omega,\right. \\
=\left\{\bar{R}_{T}(+\Omega,+\right. & \left.\Omega^{\prime \prime}\right)\left\{\bar{S}_{w}\left(\tau_{w},+\Omega^{\prime \prime},-\Omega^{\prime}\right)\right. \\
& \left.\left.\times \bar{R}_{T}\left(-\Omega^{\prime},-\Omega_{0}\right)\right\}\right\}+\cdots
\end{aligned}
$$

\section{Radiance}

The upwelling radiance at the top of the atmosphere was calculated at wavelength 0.63 $\mu \mathrm{m}$, which corresponds to the center of the wavelength range of channel $1(0.58-0.68 \mu \mathrm{m})$ of the AVHRR radiometer on board the NOAA-7 satellite. This wavelength region is slightly off that of maximum transparency for clear ocean water (about $0.46 \mu \mathrm{m}$ ) (Plass et al., 1976). The vertical concentration profile of aerosols was given by McClatchy et al. (1972). Visibility of the atmosphere is $23 \mathrm{~km}$ (clear condition). The aerosols are assumed to be spherical and their size distribution was also given by the authors $(0.1 \mu \mathrm{m} \leqq n(r) \leqq 10.0 \mu \mathrm{m})$, where the aerosol size distribution function is the same at all altitudes. The scattering phase function was computed based on the refractive index of water $(m=1.332-i 0.0)$ given by Hale and Querry (1973). The optical thicknesses of atmospheric constituents such as aerosols $\left(\tau_{A}\right)$, molecules $\left(\tau_{R}\right)$ and ozone $\left(\tau_{3}\right)$ are given by $\tau_{A}=0.150, \tau_{R}=0.057$, and $\tau_{3}=$ 0.030 . Upon computing the emergent radiation, the inhomogeneous atmosphere was simulated by 9 homogeneous sub-layers. The ocean surface was simulated by many facets whose slopes are according to the isotropic Gaussian distribution (Cox and Munk, 1956). The ocean was assumed to be homogeneous and its bottom was assumed to absorb all incident radiation. The optical properties of hydrosols and chlorophyll are not readily available. Therefore in this computation, the optical thickness due to water and hydrosols 
was assumed to be 5.14 , whereas water scatters the incident radiation according to the Rayleigh law. The scattering optical thickness by water was 0.94 . These values correspond to a geometrical depth of about $20 \mathrm{~m}$ at wavelength $\lambda=0.63 \mu \mathrm{m}$ (Raschke, 1972).

A case of the ocean surface wind $1 \mathrm{~m} / \mathrm{sec}$ under a clear condition is shown for evaluating the effect of the scatterings in the ocean. The upwelling radiance at the top of the atmosphere is given in the principal plane with the solar horizon on the left of Fig. 3, the nadir at the center, and the anti-solar horizon on the right.

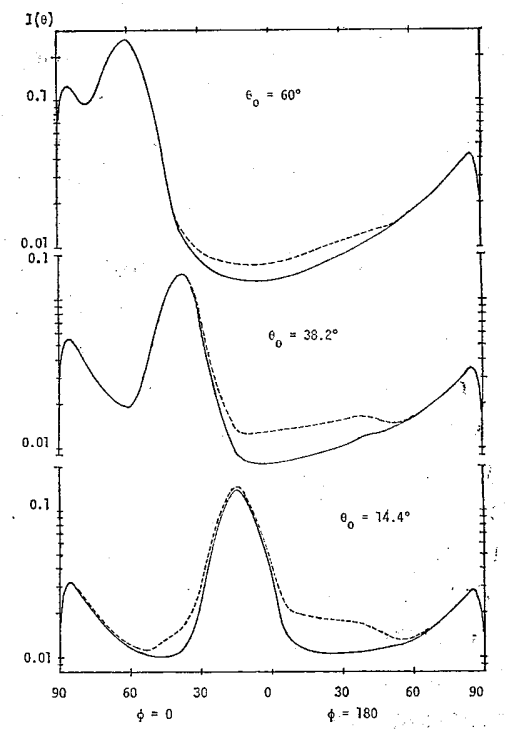

Fig. 3. Radiance with the effect of reflection in the ocean at the top of the atmosphere in the sun vertical plane. Dashed and solid curve respectively indicate radiance with and without the effect of reflection in the ocean. Abscissa shows the nadir angle of observation, ordinate the intensity of reflected radiation (incident solar flux is normalized to be 1 ).

To evaluate the effect of radiation from the ocean, computations in scalar form are carried out as a first step.

Solar zenith angles $\theta_{0}$ of $14.39^{\circ}, 38.23^{\circ}$ and $60^{\circ}$ are shown. Dashed and solid lines correspond to the computational results with and without the effect of scatterings in the ocean. $2 \%, 3 \%$ and $10 \%$ of the incident radiation are reflected by the ocean surface at $\theta=14^{\circ}, 46^{\circ}$ and $66^{\circ}$, respectively, if the ocean surface reflects light according to the reflectivity based on the refractive index of water (Takashima and Takayama, 1982). Therefore $98 \%, 97 \%$ and $90 \%$ of the incident radiation is penetrated into the ocean for corresponding incident directions. Around the specular direction, a strong sun glitter is noted. The intensity is relatively high at the higher zenith angles of observation due to scatterings in the atmosphere and the high reflectivity of the ocean surface. The effect of the scatterings in the ocean is strong at the smaller nadir angles of observation. The intensity of reflected radiation is 0.1446 and 0.1374 at the direction of the sun glitter $\left(\theta_{0}=14.39^{\circ}\right)$ with and without the effect (see Fig. 3), respectively. The difference is $5 \%$. No appreciable effect is seen when the nadir angle of observation is large.

\section{Conclusion}

A method of computing the atmospheric effects on the upwelling radiation from the ocean is derived in a form suitable for the use of the adding method. This effect $\bar{S}_{w}^{u}$ can be expressed in a form additive to the reflection matrix of the ocean surface $\bar{R}$. Therefore it is rather simple to handle. Polarization due to scatterings in the ocean was included in the derivation of the equation. As an example, a simple ocean model (Raschke, 1972) is demonstrated numerically at $0.63 \mu \mathrm{m}$ in scalar form. Computations show that the effect of the reflection in the ocean is strong at a small nadir angle of observation, whereas no appreciable effect is seen when the nadir angle of observation is wide. Computations including the effect of polarization are under way.

Acknowledgement:-The author wishes to express his thanks to Prof. S. Ueno of the Kanazawa Institute of Technology for his encouragement throughout this work. He owes much to Mr. Y. Takayama of the Meteorological Research Institute for his useful suggestions about computations. 


\section{References}

Cox, C. and W. Munk, 1955: Some problems in optical oceanography. J. Mar. Res. 14, 63-78.

Hale, G.M. and M.R. Querry, 1973: Optical constants of water in the $200-\mathrm{nm}$ to $200-\mu \mathrm{m}$ wavelength region, Appl. Opt., 12, 555-563.

McClatchey, R. A., R. W. Fenn, J.E. A. Selby, F.E. Volz and J.S. Garing, 1972: Optical properties of the atmosphere (3rd edition). AFCRL-720497, Air Force Cambridge Research Lab., L. G. Hanscom Field, Bedford MA, 108pp.

Plass, G. N., G. W. Kattawar and J. A. Guinn, Jr., 1976: Radiance distribution over a ruffled sea : Contributions from glitter, sky, and ocean, Appl. Opt. 15, No. 12, 3161-3165.

Raschke, E., 1972: Multiple scattering calculation of the transfer of solar radiation in an atmosphere-ocean system, Beitrage zur Physik der Atmosphere, 45, Band, S. 1-19.

Sekera, Z., 1966: Reduction of the equations of radiative transfer for a plane-parallel, planetary atmosphere Part 1, RAND Memorandum RM4951-PR.

Takashima, T., 1973: Emergent radiation from an inhomogeneous, plane-parallel planetary atmosphere calculated by using the "adding" method, J. Quant. Spectrosc. Radiat. Transfer, 13, 12291232.

1975: A new approach of the adding method. for the computations of emergent radiation of inhomogeneous plane-parallel planetary atmosphere, Astrophy. Space Sci., 36, 319-328.

and Y. Takayama, 1981: Emissivity and reflectance of model sea surface for the use of AVHRR data of NOAA satellites, Papers in Met. \& Geophys., 32, 267-274.

Tanaka, M. and T. Nakajima, 1977: Effects of oceanic turbidity and index or refraction of hydrosols on the flux of solar radiation in the atmosphere-ocean system, J. Quant. Spectrosc. Radiat. Transfer, 18, 93-111.

Ueno, S., 1960: The probabilistic method for problems of radiative transfer. X. Diffuse reflection and transmission in a finite inhomogeneous atmosphere, Astrophys. J., 132, No. 3, 729-745. 1981: Retrieval of coastal water information from Landsat MSS data, Proceedings of 7 th International symposium on Machine processing of remotely sensed data, Purdue Univ., 703-710.

\section{海からの放射の大気散乱光に及ぼす影響の新しい計算法}

$$
\text { 高島勉 }
$$

海からの放射の大気散乱光に及ぼす影響を adding method に使える形で導いた。大気及び海水は水平方向に光 学的に一様で, 垂直方向に不均質であると仮定した。海面は Cox and Munk (1956) のモデルとし, 海底は黑体 とした。海中の海水, hydrosol, chlorophyll 等によって散乱, 反射した光は偏光を考慮した形で式を導いたが, 計算例としては Raschke (1972) のモデルを scalar で求め，衛星によって受信される反射光の強度 (0.63 $\mu \mathrm{m}$ : NOAA 搭載 AVHRR 放射計の第 1 チャンネルの中心波長に対応）への影響として討議した。海中からの放射は天 底角が小さい所で認められ，天底角が大きくなると影響がない事がわかった。偏光を考慮した計算結果は準備中で के。 